\title{
Alkaline phosphatase in metastatic castration-resistant prostate cancer: reassessment of an older biomarker
}

\author{
Daniel Heinrich*,1, Øyvind Bruland ${ }^{2}$, Theresa A Guise ${ }^{3}$, Hiroyoshi Suzuki ${ }^{4}$ \& Oliver Sartor ${ }^{5}$ \\ ${ }^{1}$ Department of Oncology, Akershus University Hospital, Sykehusveien 25, 1478 Lørenskog, Norway \\ ${ }^{2}$ Department of Oncology, Oslo University Hospital-Norwegian Radium Hospital, Ullernchausseen 70, 0379 Oslo, Norway \\ ${ }^{3}$ Department of Medicine, Indiana University School of Medicine, 980 W. Walnut St, Walther Hall, R3, Room C130 Indianapolis, IN \\ 46202, USA \\ ${ }^{4}$ Department of Urology, Toho University Sakura Medical Center, 564-1 Shimazu, Sakura-shi, Chiba 285-8741, Japan \\ ${ }^{5}$ Departments of Medicine \& Urology, Tulane Cancer Center, 1430 Tulane Ave., SL-42, New Orleans, LA 70112, USA \\ *Author for correspondence: Tel.: +47 913 95554; daniel.heinrich@ahus.no
}

Since most patients with metastatic castration-resistant prostate cancer (MCRPC) have bone metastases, it is important to understand the potential impact of therapies on prognostic biomarkers, such as ALP. Clinical studies involving MCRPC life-prolonging agents (i.e., sipuleucel-T, abiraterone, enzalutamide, docetaxel, cabazitaxel, and radium-223) have shown that baseline ALP level is prognostic for overall survival, and may be a better prognostic marker for overall survival than prostate-specific antigen in patients with bone-dominant mCRPC. Mechanism of action differences between therapies may partly explain ALP dynamics during treatment. ALP changes can be interpreted within the context of other parameters while monitoring disease activity to better understand the underlying pathology. This review evaluates the current role of ALP in $\mathrm{MCRPC}$.

First draft submitted: 30 January 2018; Accepted for publication: 23 May 2018; Published online: 21 June 2018

Keywords: alkaline phosphatase $\bullet$ biomarker $\bullet$ bone metastases $\bullet$ castration-resistant prostate cancer $\bullet$ mechanism of action • prognostic marker • survival

Prostate cancer has a propensity to metastasize to the bone and locally disrupt normal bone remodeling [1,2]. Bone metastases develop through hematogenous dissemination, predominantly to the red marrow elements of the axial skeleton, where they cause an imbalance between osteoclast-mediated bone resorption and osteoblastmediated bone formation [3]. In prostate cancer, bone metastases are predominantly characterized by an osteoblastic phenotype, with evidence of increased bone formation and sclerosis on radiography [4-6]. Enhanced osteoclastic bone resorption is also common. Since approximately $90 \%$ of patients with metastatic castration-resistant prostate cancer (mCRPC) have radiologic evidence of bone metastases $[7,8]$, it is important to understand the mechanisms of bone disease and the potential impact of therapies on prognostic biomarkers, such as ALP.

This review examines the sources and prognostic value of ALP in bone-dominant mCRPC, and presents guidance on the value of ALP as a biomarker in mCRPC. Furthermore, it describes the mechanisms of action of survivalprolonging drugs in mCRPC, specifically regarding the potential impact on ALP dynamics; evaluates ALP data from clinical trials of agents that confer a survival advantage in mCRPC; and considers whether different therapy mechanisms of action can explain ALP clinical data.

\section{ALP in bone-metastatic CRPC}

ALP originates primarily from the liver and bone [3], with bone-specific ALP (bALP) accounting for 40-50\% of ALP levels in healthy adults. bALP is an enzyme that is expressed on the surface of osteoblasts [1]. It contributes to the mineralization of newly laid type 1 collagen-rich bone matrix, and its expression mirrors an osteoblastic stroma undergoing microcalcification [9]. Increased bALP levels can indicate either a disease state or healing that is occurring within the bone [9].

Future $\because$ Medicine 
bALP level is used as a bone turnover marker reflective of a combination of osteoblastic activity and extent of disease (i.e., volume of metastases) in patients with bone-dominant mCRPC $[1,4]$. As bone metastases develop, bALP is released into the blood and urine [3]. In the absence of extensive liver disease, bALP is the primary component of serum total ALP (tALP) levels measured in patients with mCRPC [10]. bALP can be used as a serum marker of increased osteoblast activity, with its secretion indicating the presence of proliferating osteoblasts.

Cross-talk between tumor cells and the bone microenvironment disrupts normal bone remodeling, leading to a 'vicious cycle', as explained below, which further fuels tumor growth in bone $[1,2,11,12]$. Sources of ALP in the pathologic state are not fully known, but it is thought to originate primarily from increased activation of osteoblasts, with potentially direct expression also in prostate cancer cells $[13,14]$. Prostate cancer bone metastases activate osteoblasts, leading to the release of ALP during new bone formation. Prostate cancer cells also secrete factors that activate stromal cells in the bone microenvironment and stimulate osteoblast activity [4]. For example, bone morphogenetic proteins and sonic hedgehog provide a favorable environment for the growth and survival of prostate cancer cells, promoting osteoblast differentiation and expression of osteoblastic markers, including ALP [4].

Prostate cancer cells can develop an osteoblast-like cell phenotype within the bone microenvironment, potentially contributing directly to increased ALP levels [13,14]. Bone-metastatic prostate cancer cells are osteomimetic, may develop osteoblastic properties through independent activation of ERK and Notch signaling, and are capable of expressing genes and proteins typically expressed by osteoblasts [5]. Cross-talk between prostate tumor cells and osteoblasts promotes osteomimicry [15], a condition in which prostate cancer cells achieve stem cell properties of bone marrow mesenchymal stem cells and often express osteoblastic markers [16. For example, the C4-2B human prostate cancer cell line that metastasizes to bone has attributes of an osteoblast phenotype not present in the parental LNCaP cell line, which does not metastasize to the bone [14]. C4-2B cells are able to induce mineralization and gain an osteoblast phenotype that produces ALP in vitro, suggesting (but not proving) that prostate cancer cells in bone metastases contribute directly to the mineral formation found in osteoblastic lesions and the bALP levels in serum.

\section{Clinical importance of ALP}

ALP is a prognostic biomarker in mCRPC, reflecting disease outcome independent of therapy [17]. Measuring tALP levels is inexpensive and readily available. In patients with mCRPC, high baseline ALP levels are associated with negative outcomes, including skeletal complications and decreased survival [18-20]. Moreover, elevated ALP levels have also been correlated with the extent of metastatic bone disease [12,20]. Changes in ALP levels may reflect changes in bone turnover and osteoblastic activity.

The use of baseline ALP level as a prognostic marker for overall survival (OS) in patients with mCRPC has been confirmed in multivariate analyses and multiple prognostic models independent of therapy selection [21-24]. Importantly, baseline ALP is a relevant prognostic marker for OS in bone-dominant mCRPC, along with others (e.g., prostate-specific antigen [PSA]) [7,25]. Studies of ALP after treatment are more limited, and the utility of changes in ALP as a marker post-therapy has yet to be completely explored.

A retrospective study that evaluated whether ALP kinetics were prognostic for bone metastasis and death in patients with CRPC indicated that ALP velocity (the slope of the linear regression line of all ALP values overtime) was an independent prognostic factor for OS and bone metastases-free survival in mCRPC patients [26]. Similar findings were observed in an independent dataset [27]. Monitoring ALP levels in mCRPC can provide prognostic information about the likely outcome of the disease [28], but changes in ALP have not been validated as a surrogate for effectiveness of mCRPC therapy [29].

\section{Mechanism of action impact on ALP levels}

Six drugs are currently approved for the treatment of mCRPC, based on their ability to prolong survival versus placebo or active comparator in Phase III clinical trials: sipuleucel-T, abiraterone acetate, enzalutamide, docetaxel, cabazitaxel, and radium-223 dichloride. These survival-prolonging drugs have their unique mechanisms of action that correspond to different effects on ALP levels during treatment, and they represent opportunities for sequencing and combination strategies in mCRPC treatment, although combinations have yet to be proven effective. The mechanism of action for each drug and potential impact on ALP levels are summarized in Table 1 [30-62]. 


\begin{tabular}{|c|c|c|c|c|c|}
\hline $\begin{array}{l}\text { Survival-prolonging } \\
\text { mCRPC drugs }\end{array}$ & Drug class & US FDA-approved indication & Mechanism of action & $\begin{array}{l}\text { Impact on ALP levels in } \\
\text { patients with mCRPC }\end{array}$ & Ref. \\
\hline Sipuleucel-T & Immunotherapy & $\begin{array}{l}\text { For the treatment of } \\
\text { asymptomatic or minimally } \\
\text { symptomatic mCRPC }\end{array}$ & $\begin{array}{l}\text { Autologous cellular } \\
\text { immunotherapy }\end{array}$ & $\begin{array}{l}\text { Clinical impact on ALP } \\
\text { levels not likely }\end{array}$ & [30-34] \\
\hline $\begin{array}{l}\text { Abiraterone acetate } \\
\text { (abiraterone) }\end{array}$ & Hormonal therapy & $\begin{array}{l}\text { In combination with prednisone } \\
\text { for treatment of patients with } \\
\text { mCRPC }\end{array}$ & CYP17 inhibitor & $\begin{array}{l}\text { Indirect effect: ALP levels } \\
\text { decrease as tumor burden } \\
\text { decreases }\end{array}$ & [35-40] \\
\hline Enzalutamide & Hormonal therapy & $\begin{array}{l}\text { For treatment of patients with } \\
\text { mCRPC }\end{array}$ & $\begin{array}{l}\text { Androgen receptor } \\
\text { inhibitor }\end{array}$ & $\begin{array}{l}\text { Indirect effect: ALP levels } \\
\text { decrease as tumor burden } \\
\text { decreases }\end{array}$ & [41-44] \\
\hline Docetaxel & Taxane chemotherapy & $\begin{array}{l}\text { In combination with prednisone } \\
\text { for treatment of patients with } \\
\text { mCRPC }\end{array}$ & Microtubule inhibitor & $\begin{array}{l}\text { Indirect effect: ALP levels } \\
\text { decrease as tumor burden } \\
\text { decreases }\end{array}$ & [45-50] \\
\hline Cabazitaxel & Taxane chemotherapy & $\begin{array}{l}\text { In combination with prednisone } \\
\text { for treatment of patients with } \\
\text { mCRPC previously treated with a } \\
\text { docetaxel-containing treatment } \\
\text { regimen }\end{array}$ & Microtubule inhibitor & $\begin{array}{l}\text { Indirect effect: ALP levels } \\
\text { decrease as tumor burden } \\
\text { decreases }\end{array}$ & [51-54] \\
\hline $\begin{array}{l}\text { Radium-223 dichloride } \\
\text { (radium-223) }\end{array}$ & Targeted alpha therapy & $\begin{array}{l}\text { For treatment of patients with } \\
\text { CRPC, symptomatic bone } \\
\text { metastases, and no known } \\
\text { visceral metastatic disease }\end{array}$ & $\alpha$-particle emission & $\begin{array}{l}\text { Direct effect: ALP levels } \\
\text { decrease as bone } \\
\text { formation is reduced via } \\
\text { microenvironmental effect }\end{array}$ & [55-62] \\
\hline
\end{tabular}

\section{Immunotherapy}

Sipuleucel-T

Sipuleucel- $T$ is an autologous cellular immunotherapy that uses a patient's own cells to stimulate an immune response against prostatic acid phosphatase to target and remove prostate cancer cells, thereby inducing a systemic immune response against the patient's prostate cancer cells that express prostatic acid phosphatase (Table 1) [30-33]. The effect of sipuleucel-T may lead to antigen shedding, causing an even broader antitumor immune response [32]. The mechanism of action of sipuleucel-T does not suggest a direct impact on ALP levels when the agent is used to treat the patients with mCRPC [63].

\section{Hormonal therapy \\ Abiraterone acetate}

Abiraterone acetate (abiraterone) is a selective, irreversible inhibitor of CYP17 [35-39]. When hydrolyzed, this oral prodrug converts to its active metabolite abiraterone and inhibits androgen biosynthesis (Table 1). Abiraterone is taken with prednisone or prednisolone to address the imbalance of mineralocorticoid activity that occurs with CYP17 targeting. CYP17 is expressed during osteoclast and osteoblast maturation, and abiraterone has been shown to inhibit osteoclast maturation and also promote osteoblast differentiation and ALP upregulation in an in vitro study of human primary osteoclasts and osteoblasts [38]. Given its mechanism of action, abiraterone is not expected to directly decrease ALP levels when used to treat mCRPC patients; however, an indirect effect will likely occur as the tumor burden decreases and bone healing occurs. Clinical experience has shown that ALP levels may increase initially after starting abiraterone (e.g., first 2-6 weeks) and later decrease in mCRPC patients who respond to therapy. The initial increase is likely attributable to healing bone and is often noted in patients with a sharp decline in PSA levels.

\section{Enzalutamide}

Enzalutamide is an androgen receptor inhibitor that acts on different steps in the androgen receptor signaling pathway (Table 1) [41-43]. Enzalutamide competitively inhibits androgen binding to androgen receptors and inhibits androgen receptor nuclear translocation and interaction with DNA. It ultimately results in decreased cell growth and apoptosis of prostate cancer cells, leading to decreased mCRPC tumor volume [41-43]. The mechanism of action of enzalutamide is not expected to directly decrease ALP levels when the agent is used to treat mCRPC patients; however, an indirect effect will likely occur as the tumor burden decreases. As with abiraterone, clinical experience 
has shown that ALP levels may increase initially after starting enzalutamide (e.g., first 2-6 weeks) and later decrease in mCRPC patients who respond to therapy. The mechanism underlying ALP change in enzalutamide-treated patients is likely similar to that of abiraterone. Initial increases in ALP are likely due to healing bone; subsequent decreases occur over time as bone remodeling diminishes as a consequence of antitumor activity.

Taxane chemotherapies

Docetaxel

Docetaxel is a semisynthetic taxane, with several mechanisms of action being proposed to account for its antineoplastic activity in prostate cancer (Table 1) [45-49]. Most notably, docetaxel disrupts mitosis, promoting apoptotic cell death [45-47]. It is also thought to affect androgen signaling in prostate cancer cells, leading to downregulation of androgen receptors and decreased secretion of PSA [47-49]. Given its mechanism of action, the effects of docetaxel on ALP are indirect, with changes in the tumor causing alterations in ALP levels via the microenvironmental changes that occur as a function of antitumor effects. ALP 'flares', as seen with abiraterone and enzalutamide during the first weeks of treatment, are less common during treatment with docetaxel.

\section{Cabazitaxel}

Cabazitaxel is a semisynthetic taxane whose antitumor mechanism of action is similar to that of docetaxel (Table 1) [51-53]. It is structurally distinct from docetaxel, with a slightly larger biochemical structure. Unlike other taxanes, cabazitaxel has a low affinity for P-glycoprotein 1, a drug efflux pump thought to contribute to docetaxel resistance [51-53]. As with docetaxel, cabazitaxel's mechanism of action suggests an indirect effect on ALP levels.

Targeted alpha therapy

Radium-223 dichloride

Radium-223 dichloride (radium-223) is a targeted alpha therapy that mimics calcium to accumulate in sites of active bone remodeling (Table 1) [55-60]. It emits high-energy, short-range $(<100 \mu \mathrm{m}) \alpha$ particles to induce doublestranded DNA breaks in target cells. Prostate cancer models have shown that radium-223 induces such DNA damage in tumor cells, osteoblasts, and osteoclasts, suggesting direct radiation effects on both tumor and bone microenvironment during osseous tumor growth [59]. This dual-targeting mechanism of action inhibits disease progression through cytotoxic effects on tumor cells and stabilization of the bone microenvironment in bone metastases. Similar findings were observed in a mouse model of breast cancer bone metastases, suggesting efficacy regardless of primary tumor origin [60]. Radium-223 has also been shown to be associated with immunogenic cell death in vitro in human prostate cancer cell lines, but the contribution of this effect in vivo is unknown [61]. The radium-223 mechanism of action reduces bone formation, directly decreasing ALP levels during treatment in mCRPC patients. Clinical experience has shown that ALP levels decrease rapidly and usually without any 'flare' after initiation of radium-223 treatment, but increase again after completion of the therapeutic regimen [64-66].

\section{Denosumab \& zoledronic acid}

The bone-targeting agents denosumab and zoledronic acid are distinct from the six survival-prolonging drugs mentioned above (Table 1), in that clinical studies have not demonstrated a survival benefit when these drugs are used to treat patients with mCRPC [6]. Their use as supportive agents in patients with mCRPC does impact ALP levels, and because most patients will receive denosumab or zoledronic acid in addition to survival-prolonging anticancer drugs, their mechanisms of action and potential impact on ALP levels are worth noting. During treatment, changes in ALP levels will likely be driven both by denosumab or zoledronic acid and by the survival-prolonging anticancer drugs, and probably to different extents.

Denosumab binds to RANKL, preventing the binding of RANKL to RANK, thus inhibiting the formation and activation of osteoclasts. Zoledronic acid binds to mineralized bone matrix and reduces osteoclast activity by inducing osteoclast apoptosis [6]. Since ALP levels increase when bone destruction is linked to bone formation (e.g., high-turnover osteoporosis), use of these bone resorption inhibitors in patients with mCRPC may contribute to decreased ALP levels.

\section{ALP \& life-prolonging mCRPC therapies}

This section reviews results from trials involving drugs that have shown life-prolonging ability for patients with mCRPC, with a special emphasis on ALP data. 
Table 2. Trials indicating a prognostic value for alkaline phosphatase level in overall survival of patients with

metastatic castration-resistant prostate cancer treated with the survival-prolonging agents.

\begin{tabular}{|c|c|c|c|c|c|c|}
\hline Trial $^{\dagger}$ & Study design & $\mathrm{n}$ & Treatment & Prognostic factor & $\begin{array}{l}\text { HR for OS }(95 \% \mathrm{Cl}) \\
\text { p-value }\end{array}$ & Ref. \\
\hline \multicolumn{7}{|l|}{ Sipuleucel-T } \\
\hline George et al. & $\begin{array}{l}\text { Pooled data from three } \\
\text { Phase III trials }\end{array}$ & 249 & $\begin{array}{l}\text { Crossover from control arm } \\
\text { to sipuleucel-T }\end{array}$ & - Baseline ALP & $\begin{array}{l}\text { - NA; independent } \\
\text { predictor of } \\
\text { postprogression survival } \\
(p<0.1)^{\ddagger}\end{array}$ & [67] \\
\hline Bilen et al. & Retrospective analysis & 56 & Sipuleucel-T & - Baseline ALP (>90 vs $\leq 90 \mathrm{IU} / \mathrm{l}$ ) & $-8.7(1.7-46) ; p<0.01^{\ddagger}$ & [63] \\
\hline \multicolumn{7}{|c|}{ Abiraterone acetate (abiraterone) } \\
\hline $\begin{array}{l}\text { Fizazi et al. } \\
\text { (COU-AA-301 } \\
\text { trial) }\end{array}$ & $\begin{array}{l}\text { Phase III: patients } \\
\text { previously treated with } \\
\text { docetaxel (final analysis) }\end{array}$ & 1195 & $\begin{array}{l}\text { Abiraterone }+ \text { prednisone } \\
\text { vs placebo }+ \text { prednisone }\end{array}$ & $\begin{array}{l}\text { - Baseline ALP }>\text { median } \\
\text { - Baseline ALP }<\text { median }\end{array}$ & $\begin{array}{l}-0.60(0.50-0.74) \\
-0.88(0.69-1.12)\end{array}$ & [68] \\
\hline Chi et al. & Prognostic model & 762 & Abiraterone + prednisone & $\begin{array}{l}\text { - Baseline ALP (>ULN [160 IU/I] } \\
\text { vs } \leq \text { ULN) }\end{array}$ & $\begin{array}{l}-2.02(1.69-2.41) \\
p<0.0001^{\S} \\
-1.38 ; p=0.0016^{\ddagger}\end{array}$ & [69] \\
\hline $\begin{array}{l}\text { Ryan et al. } \\
\text { (COU-AA-302 } \\
\text { trial) }\end{array}$ & $\begin{array}{l}\text { Phase III: } \\
\text { chemotherapy-naive } \\
\text { patients (final analysis) }\end{array}$ & 1088 & $\begin{array}{l}\text { Abiraterone }+ \text { prednisone } \\
\text { vs placebo }+ \text { prednisone }\end{array}$ & - Baseline ALP & $\begin{array}{l}\text { - NA; significantly } \\
\text { prognostic } \ddagger\end{array}$ & [70] \\
\hline Mikah et al. & Retrospective analysis & 84 & Abiraterone + prednisone & $\begin{array}{l}\text { - Increase in baseline ALP after } \\
12 \text { wk (yes vs no) } \\
\text { - No ALP flare vs ALP flare }\end{array}$ & $\begin{array}{l}-4.9(2.7-8.9) ; p<0.001^{\S} \\
-3.1(1.7-5.7) ; p<0.001^{\S}\end{array}$ & [71] \\
\hline \multicolumn{7}{|l|}{ Docetaxel } \\
\hline $\begin{array}{l}\text { Armstrong et al. } \\
\text { (TAX327 trial) }\end{array}$ & $\begin{array}{l}\text { Multivariate model from } \\
\text { Phase III trial }\end{array}$ & 1006 & $\begin{array}{l}\text { Docetaxel }+ \text { prednisone vs } \\
\text { mitoxantrone }+ \text { prednisone }\end{array}$ & - Baseline ALP & $\begin{array}{l}-1.27 \text { per log rise } \\
(1.15-1.39) ; p<0.001^{\ddagger}\end{array}$ & [72] \\
\hline $\begin{array}{l}\text { Armstrong et al. } \\
\text { (TAX327 trial) }\end{array}$ & $\begin{array}{l}\text { Multivariate model from } \\
\text { Phase III trial }\end{array}$ & 604 & $\begin{array}{l}\text { Docetaxel }+ \text { prednisone vs } \\
\text { mitoxantrone }+ \text { prednisone }\end{array}$ & $\begin{array}{l}\text { - Baseline ALP ( }<200 \text { vs } \\
200-1000 \text { IU /dI) } \\
\text { - Baseline ALP ( }<200 \text { vs }>1000 \\
\text { IU/dl) }\end{array}$ & $\begin{array}{l}-1.26(1.02-1.55) ; \\
p=0.033^{\ddagger} \\
-1.55(1.11-2.21) ; \\
p=0.012^{\ddagger}\end{array}$ & [73] \\
\hline $\begin{array}{l}\text { Sonpavde et al. } \\
\text { (TAX327 trial) }\end{array}$ & Retrospective analysis & 601 & $\begin{array}{l}\text { Docetaxel + prednisone vs } \\
\text { mitoxantrone + prednisone }\end{array}$ & $\begin{array}{l}\text { - Normalization of ALP } \\
\text { ( }<120 \mathrm{U} / \mathrm{l} \text { ) by day } 90 \text {, adjusted } \\
\text { for } \geq 30 \% \text { PSA decrease } \\
\text { - Any increase in ALP by day } 90 \text {, } \\
\text { adjusted for } \geq 50 \% \text { PSA increase }\end{array}$ & $\begin{array}{l}-0.79(0.65-0.97) ; \\
p=0.022^{\ddagger} \\
-1.64(1.28-2.10) ; \\
p<0.001^{\ddagger}\end{array}$ & [74] \\
\hline \multicolumn{7}{|l|}{ Cabazitaxel } \\
\hline $\begin{array}{l}\text { Bahl et al. } \\
\text { (TROPIC trial) }\end{array}$ & 2-year follow-up & 755 & $\begin{array}{l}\text { Cabazitaxel }+ \text { prednisone vs } \\
\text { mitoxantrone }+ \text { prednisone }\end{array}$ & - Baseline ALP & $\begin{array}{l}-[\text { OR: } 0.95(0.92-0.98) ; \\
p<0.001]^{\ddagger}\end{array}$ & [75] \\
\hline $\begin{array}{l}\text { van Soest } \\
\text { (CABARESC trial) }\end{array}$ & Phase II (postdocetaxel) & 114 & $\begin{array}{l}\text { Cabazitaxel }+ \text { prednisone }+ \\
\text { budesonide vs cabazitaxel }+ \\
\text { prednisone }\end{array}$ & - Baseline ALP & $\begin{array}{l}-1.84(1.31-2.60) \\
p<0.001^{\S} \\
-1.65(1.06-2.57) ; \\
p=0.026^{\ddagger}\end{array}$ & [76] \\
\hline \multicolumn{7}{|l|}{ Radium-223 } \\
\hline $\begin{array}{l}\text { Sartor et al. } \\
\text { (ALSYMPCA } \\
\text { trial) }\end{array}$ & Phase III prognostic model & 921 & $\begin{array}{l}\text { Radium-223+ BSoC vs } \\
\text { placebo }+ \text { BSoC } \mathbb{I}\end{array}$ & $\begin{array}{l}\text { - Total ALP\# } \\
\text { - tALP decline }\end{array}$ & $\begin{array}{l}-2.017 ; p<0.0001 \\
-0.45(0.34-0.61) ; \\
p<0.0001^{\ddagger}\end{array}$ & [65] \\
\hline \multicolumn{7}{|c|}{$\begin{array}{l}\text { †Enzalutamide is not included because the literature search did not identify any trials or analyses that evaluated the prognostic value of ALP for overall survival. } \\
\text { ¥Multivariate analysis. } \\
\text { ¿Univariate analysis. } \\
\text { I Log transformation due to heavily skewed distribution (ten-fold increase). } \\
\text { \#Overall intention to treat population. } \\
\text { BSoC: Best standard of care; HR: Hazard ratio; mCRPC: Metastatic castration-resistant prostate cancer; NA: Not available; OR: Odds ratio; OS: Overall survival; PSA: Prostate-specific } \\
\text { antigen; ULN: Upper limit of normal. }\end{array}$} \\
\hline
\end{tabular}

\section{Sipuleucel-T}

Limited ALP data are available from trials with sipuleucel-T in mCRPC patients (Table 2 [63,65,67-76]) [63,67,77,78]. In the Phase III IMPACT trial [77], sipuleucel-T efficacy was observed in mCRPC patients regardless of baseline ALP level. In another Phase III trial $(\mathrm{n}=127)$, although median baseline ALP values were reported, no additional ALP analyses or analysis of the prognostic value of this biomarker was reported [78]. However, two studies have demonstrated the prognostic value of ALP in sipuleucel-T-treated patients, including one study that investigated the impact of control-arm crossover to salvage immunotherapy in patients who progressed after completing one of three Phase III trials with sipuleucel-T [67]. In this study, multivariate analysis identified lower baseline ALP 
values as a potential indicator of survival $(\mathrm{p}<0.1)$. In another retrospective study of 56 CRPC patients treated with sipuleucel-T, multivariate analysis using a Cox proportional hazards regression model indicated that baseline ALP $>90 \mathrm{U} / 1$ was significantly associated with worse OS $(\mathrm{p}=0.01)$ [63]. There is a lack of data on ALP dynamics during sipuleucel-T treatment in the published literature.

\section{Abiraterone acetate}

Abiraterone clinical trials evaluated efficacy of the drug in MCRPC patients according to baseline ALP levels, and examined the potential of ALP as a prognostic biomarker [68-71,79-83]. The Phase III COU-AA-301 trial randomized patients with mCRPC previously treated with docetaxel to prednisone plus abiraterone or placebo [68,80]. Both interim (median: 12.8 months) [80] and final (median: 20.2 months) [68] analysis of data from this trial showed that abiraterone prolonged OS regardless of whether a patient had baseline ALP levels above or below the median: value (hazard ratio $[\mathrm{HR}]<1$ for both ALP subgroups; Table 2). Using data from this trial, a univariate Cox model (HR: 2.02, 95\% CI: 1.69-2.41; $\mathrm{p}<0.0001$ ) and multivariate Cox model with a stepwise procedure (HR: 1.38; $\mathrm{p}=0.0016$ ) indicated that baseline ALP (> upper limit of normal [ULN; $160 \mathrm{IU} / \mathrm{l}] \mathrm{vs} \leq \mathrm{ULN}$ ) was prognostic for OS [69]. Another exploratory analysis of the COU-AA-301 study that evaluated pain control found no difference in baseline ALP levels between treatment groups for patients with or without baseline pain [81]. However, the potential correlation between pain palliation and serum ALP was not analyzed.

The Phase III COU-AA-302 trial in chemotherapy-naive patients with mCRPC patients indicated that the treatment effect of abiraterone on OS was favorable (both HRs <1.0), regardless of baseline ALP level, at both the interim [79,82] and final analyses [70]. Multivariate analysis also determined that baseline ALP was significantly prognostic for OS in these patients (Table 2) [70,79].

Another study retrospectively analyzed data from 84 patients with mCRPC treated for a median of 14 months with abiraterone plus prednisone [71]. According to univariate analysis, the absence of an increase in ALP levels during the first 2-4 weeks of abiraterone treatment (followed by a decline within 8 weeks) and rising ALP levels at 12 weeks, together with a lack of $\geq 50 \%$ decrease in PSA, were prognostic indicators of a higher risk of progressive disease and poorer OS (Table 2). However, multivariate analysis only identified a lack of $\geq 50 \%$ decrease in PSA as an independent predictor of OS [71]. In considering these results, it is important to note that prednisone can also reduce bone formation and ALP activity. The study did not recommend stopping abiraterone treatment if there was a lack of early PSA response, but did suggest following these patients closely.

A retrospective cohort study of $\mathrm{mCRPC}$ patients used a Cox proportional hazards model to analyze the association between clinical features and the duration of drug exposure [83]. According to univariate analysis, the association between low ALP levels and treatment duration failed to reach significance (HR: 1.07, 95\% CI: 0.99-1.16; $\mathrm{p}=0.074)$ [83]. In summary, these studies demonstrate that baseline ALP is a strong prognostic indicator of OS in mCRPC patients treated with abiraterone.

\section{Enzalutamide}

ALP data from trials with enzalutamide in mCRPC patients were very limited [84-86]. The Phase III AFFIRM trial [85], in patients with mCRPC previously treated with chemotherapy, and the PREVAIL trial [84], in chemotherapy-naive CRPC patients, provided no ALP data. However, a cohort study of 59 mCRPC patients treated with enzalutamide after docetaxel showed that higher median baseline ALP level was significantly associated with androgen receptor copy number gain $(p=0.003)$ [86]. Although our search results did not identify any additional enzalutamide studies containing ALP data, it is expected that baseline ALP levels would be prognostic for OS if they were evaluated in mCRPC trials with enzalutamide.

\section{Docetaxel}

Baseline ALP levels were prognostic for OS in patients with mCRPC treated with docetaxel (Table 2) [8,72,73,87-89]. Although ALP data were not reported in the large Phase III trial (e.g., Southwest Oncology Group [SWOG] 99-16 trial) [90], multivariate analyses [72,73,89] of ALP data from the Phase III TAX327 trial [8] allowed researchers to determine the data's prognostic value. Using a stratified Cox proportional hazards model, it was demonstrated that ALP was one of 10 independent baseline prognostic factors that predicted OS (HR: 1.27 per log rise; $p<0.0001$ ) (Table 2) [72]. Another multivariate analysis of TAX327 trial data also demonstrated that low pretreatment ALP levels (continuous or categorical) were prognostic of improved postprogression survival (Table 2) [73]. 
Subgroup analyses from TAX327 indicated that serum ALP changes were prognostic for OS independent of PSA [74], with normalization of ALP $(<120 \mathrm{U} / \mathrm{l})$ remaining prognostic for OS after adjusting for PSA decline $\geq 30 \%$ by day 90 (HR: $0.79,95 \%$ CI: $0.65-0.97 ; \mathrm{p}=0.022$ ) (Table 2) [74]. An increase in ALP level remained prognostic for OS after adjusting for PSA increase $\geq 50 \%$ by day 90 (HR: 1.69, 95\% CI: $1.33-2.14$; $p<0.001$ ); however, ALP changes during treatment did not meet the criteria for surrogacy for OS. Given that ALP changes did not impact the treatment effect, the authors did not recommend stopping chemotherapy solely on the basis of such changes.

A retrospective analysis of $\mathrm{mCRPC}$ patients with bone metastases who had received docetaxel-containing chemotherapy indicated that ALP was a useful biomarker to differentiate PSA flare from early PSA progression after docetaxel treatment [91]. Univariate analysis demonstrated that an initial ALP level decrease $(p=0.001)$ and change in ALP ratio $(\mathrm{p}=0.008)$ were significantly associated with a PSA flare. Multivariate analysis confirmed that a decrease in ALP level was an independent predictive factor for PSA flare $(\mathrm{p}=0.017)$.

In a retrospective trial in Japanese $\mathrm{mCRPC}$ patients receiving docetaxel-based chemotherapy, univariate analysis demonstrated that a baseline ALP level $\geq 300 \mathrm{IU} / 1$ was significantly associated with decreased OS (HR: 3.27, 95\% CI: $1.70-6.30 ; p<0.01)$; this association was not significant in multivariate analysis $(p=0.76)$ [87]. Another retrospective Japanese study, which indicated the prognostic value of baseline ALP, also demonstrated that a combination of hemoglobin, ALP, and age may assist in determining the length of optimal docetaxel regimen for patients with CRPC [92].

The initial report from the Phase III SWOG S0421 trial of docetaxel and atrasentan versus docetaxel and placebo in mCRPC patients $(n=996)$ reported no ALP data [88]; however, in a separate subanalysis $(n=778)$, Cox regression indicated that high baseline ALP level was prognostic for poorer OS (HR: 1.23, 95\% CI: 1.14-1.32) [89].

In summary, these studies demonstrate that ALP is a strong baseline prognostic indicator of OS in patients treated with docetaxel and is a potentially useful marker to monitor in patients receiving docetaxel.

\section{Cabazitaxel}

ALP data from trials with cabazitaxel in mCRPC patients focused on the prognostic potential of the biomarker [75,76,93]. The TROPIC [93] and CABARESC [76] trials (Table 2) both evaluated the prognostic value of baseline ALP levels in cabazitaxel-treated patients with mCRPC $[23,75,76,93]$. Although no ALP data were provided in the original publication of the Phase III TROPIC trial [93], multivariate logistic regression analysis of 2-year follow-up data from the trial indicated that low baseline ALP levels were positively prognostic for OS [75]. Univariate and multivariate analyses of the Phase II CABARESC trial also indicated the prognostic value of baseline ALP level for OS [76].

\section{Radium-223}

Radium-223 clinical trials evaluated efficacy of the drug in mCRPC patients according to baseline ALP levels, assessed changes in ALP dynamics during treatment, and examined the potential of ALP as a prognostic biomarker [64-66,94-101]. Due to its mechanism of action and the effect of radium-223 on ALP levels during treatment, numerous ALP data were available from mCRPC clinical trials with this agent.

Early Phase I and II trials of radium-223 showed that ALP levels declined in mCRPC patients with bone metastases [94-98], suggesting a role for this variable as a biomarker during radium-223 treatment. The efficacy of radium-223 in reducing and normalizing tALP levels was confirmed in both the Phase III ALSYMPCA trial [64] and the international expanded access program [66]. The Phase III ALSYMPCA trial demonstrated that OS was significantly prolonged with radium-223 compared with placebo in patients with ALP level $<220 \mathrm{U} / \mathrm{l}$ at baseline (HR: 0.82, 95\% CI: 0.64-1.07), as well as those with ALP $\geq 220 \mathrm{U} / \mathrm{l}$ at baseline (HR: 0.62, 95\% CI: 0.49-0.79) [64].

In an exploratory analysis of ALP, LDH, and PSA dynamics from the Phase III ALSYMPCA trial, analysis using Cox models showed baseline ALP to be a significant prognostic variable for OS (Table 2) [65]. With radium-223, tALP decreases occurred as early as 4 weeks after treatment initiation and remained low until treatment completion at 24 weeks. tALP levels remained significantly lower in the radium-223 group versus the placebo group at all time points to 46 weeks ( $p<0.001$ ). Radium-223-treated patients with a reduction in tALP from baseline to week 12 had a $55 \%$ lower risk of death versus those with no confirmed tALP decline (Table 2). Although tALP declines at 12 weeks correlated with longer OS, they did not meet statistical surrogacy requirements. Proportional treatment effect (PTE) values based on Cox regression models for tALP, LDH, and PSA changes from baseline at week 12 showed that tALP had the highest PTE, but it did not show surrogacy for OS (0.34, 95\% CI: 0-0.75); PTE values 
for LDH and PSA were 0.07 (95\% CI: 0-0.21) and 0 (95\% CI: 0-0.08), respectively. The tALP PTE score of 0.34 indicates that the tALP decrease accounted for approximately $34 \%$ of the survival benefit from radium-223 treatment [65]. In a separate analysis of the Phase III ALSYMPCA trial, baseline ALP was also a significant variable for the time to the first symptomatic skeletal event according to univariate, but not multivariate, analysis [101].

The radium-223 international expanded access program [66] also indicated the efficacy of radium-223 regardless of baseline ALP level. Median OS was longer for patients with baseline ALP levels <ULN (median: not reached; 95\% CI: 16 months-not reached) than for patients with an ALP $\geq$ ULN (median: 12 months; 95\% CI: 11-15 months). In an exploratory analysis, patients with a confirmed tALP decline at week 12 had longer OS and longer time to first symptomatic skeletal event compared with those who did not have a confirmed tALP decline [102].

Case reports have correlated changes in skeletal tumor activity on ${ }^{18} \mathrm{~F}$-choline positron emission tomography/computed tomography $\left({ }^{18} \mathrm{~F}\right.$-choline PET/CT) imaging with ALP levels in patients treated with radium-223 [99,100]. In these cases, reduction of bone-metastatic disease on ${ }^{18} \mathrm{~F}$-choline PET/CT corresponded with decreases in ALP levels.

In summary, these studies demonstrate that ALP level is a strong prognostic indicator of OS, and suggest that ALP is a useful marker to monitor disease activity during radium-223 treatment. Even more so than with the other life-prolonging agents, ALP monitoring during radium-223 treatment is notable, given the lack of correlation between PSA and outcomes.

\section{Using ALP as a biomarker}

In patients with mCRPC, changes in ALP level may reflect changes in bone turnover and osteoblastic activity indicative of the extent of bone-metastatic disease $[12,17,20]$. Decreases in ALP levels were reported to correspond with reduction of bone-metastatic disease on ${ }^{18} \mathrm{~F}$-choline PET/CT imaging [99,100]. More data are needed to evaluate imaging changes and ALP assessments. tALP measurement, which is inexpensive and readily available, can provide valuable insight into changes occurring in the bone and may aid in the diagnosis of bone metastases [18-20]. Serial ALP measurements are useful, regardless of the therapy used to treat mCRPC.

Although clinical studies involving life-prolonging agents in $\mathrm{mCRPC}$ have shown that baseline ALP level is prognostic for OS independent of therapy selection, ALP during treatment does not appear to be a confirmed predictive marker for OS. Differences in mechanism of action between the life-prolonging therapies do partly explain ALP dynamics observed during treatment, especially within the initial period after starting a new therapeutic regimen. However, clinical experience is not always reflected in theoretical models and is therefore important to keep in mind. Changes in ALP levels can help decide whether to continue treatment, particularly in the case of discordance between radiologic, clinical, and PSA evaluations.

Clinical experience has shown that ALP levels may increase initially (e.g., first 2-6 weeks) after starting treatment with abiraterone or enzalutamide, and later decrease in mCRPC patients who respond to therapy. This flare in ALP levels is not typically observed during treatment with sipuleucel-T, docetaxel, cabazitaxel, or radium-223. Sipuleucel-T is not expected to have a direct effect on ALP levels, docetaxel and cabazitaxel impact ALP levels indirectly, and radium-223 is expected to rapidly decrease ALP levels during treatment.

\section{Conclusion}

ALP is a reasonable prognostic marker that should be routinely monitored in patients with metastatic disease to the bone. Reassuring patients about monitoring changes other than PSA is a crucial part of the clinician's communication with patients and caregivers. It is not recommended that treatment be stopped solely based on changes in ALP; other indicators of disease progression are clearly needed. Continued research investigating the role of ALP as a biomarker is warranted, including evaluating the predictive value of changes in ALP levels during treatment.

\section{Future perspective}

As $\mathrm{mCRPC}$ treatment strategies continue to evolve, we anticipate that additional biomarkers will be identified to facilitate treatment decisions and that the role of current biomarkers, such as ALP, will be further clarified. The analysis of the predictive value of changes in ALP levels during treatment has until now not been investigated as a prospective end point in clinical Phase III trials, but could, given the retrospective and post hoc data mentioned in this review, become a more useful biomarker than any baseline analysis. 
Alkaline phosphatase in bone-metastatic castration-resistant prostate cancer

- bALP is an enzyme that is expressed on the surface of osteoblasts; increased levels can indicate either a disease state or healing that is occurring within the bone.

- In the absence of extensive liver disease, bALP is the primary component of serum total ALP (tALP) levels measured in patients with metastatic castration-resistant prostate cancer (mCRPC).

- bALP level is used as a bone turnover marker reflective of a combination of osteoblastic activity and extent of disease (i.e., volume of metastases) in patients with bone-dominant MCRPC.

Clinical importance of ALP

- ALP is a prognostic biomarker in MCRPC, reflecting disease outcome independent of therapy.

- High baseline ALP levels are associated with negative outcomes, including skeletal complications and decreased survival, in patients with $\mathrm{MCRPC}$.

- Baseline ALP is a relevant prognostic marker for overall survival (OS) in bone-dominant mCRPC, along with others (e.g., prostate-specific antigen).

- Changes in ALP levels may reflect changes in bone turnover and osteoblastic activity indicative of the extent of bone-metastatic disease.

Mechanism of action impact on ALP levels

- Six drugs are currently approved for the treatment of $\mathrm{MCRPC}$, based on their ability to prolong survival versus placebo or active comparator in Phase III clinical trials: sipuleucel-T, abiraterone acetate, enzalutamide, docetaxel, cabazitaxel and radium-223 dichloride.

- Differences in mechanism of action between the life-prolonging therapies may partly explain ALP dynamics observed during treatment, especially within the initial period after starting a new therapeutic regimen.

ALP and life-prolonging $\mathrm{MCRPC}$ therapies

- Clinical studies involving life-prolonging agents in MCRPC have shown that baseline ALP level is prognostic for OS independent of therapy selection; however, ALP level during treatment does not appear to be a confirmed predictive marker for OS.

Using ALP as a biomarker

- tALP measurement, which is inexpensive and readily available, can provide valuable insight into changes occurring in the bone and may aid in the diagnosis of bone metastases.

- Serial ALP measurements are useful, regardless of the therapy used to treat mCRPC.

- Monitoring ALP levels in MCRPC can provide prognostic information about the likely outcome of the disease, but changes in ALP have not been validated as a surrogate for effectiveness of mCRPC therapy.

- Reassuring patients about monitoring changes other than prostate-specific antigen is a crucial part of the clinician's communication with patients and caregivers.

- It is not recommended that treatment be stopped solely based on changes in ALP; other indicators of disease progression are clearly needed.

Financial disclosure \& competing interests disclosure

D Heinrich has received honoraria from Astellas, Bayer, Bristol-Myers Squibb, Janssen-Cilag (Johnson \& Johnson), and Novartis; has been a consultant for Bayer, Ipsen, and Roche; and has received research funding (institution) from Bayer, Janssen-Cilag (Johnson \& Johnson), Merck Sharp \& Dohme, and Roche. Ø Bruland has owned stock in Nordic Nanovector AS and Oncoinvent AS, has received honoraria and research funding (institution) from Oncoinvent AS, has been a consultant for Bayer Healthcare and has intellectual property interests with Algeta ASA/Bayer Healthcare, Nordic Nanovector AS, and Oncoinvent AS. TA Guise has been a consultant for and received research funding from Bayer HealthCare Pharmaceuticals, LLC, and has provided expert testimony for Novartis. H Suzuki has received honoraria from Takeda, Janssen, Bayer, Astellas, AstraZeneca, and Daiichi-Sankyo; has been a consultant for Janssen, Bayer, and AstraZeneca; has been on speakers bureaus for Takeda, Janssen, Bayer, Astellas, AstraZeneca, Daiichi-Sankyo, and Sanofi; and has received research funding from Takeda, Astellas, Daiichi-Sankyo, Bayer, Pfizer, Taiho, and Nihon-Kayaku. O Sartor has been a consultant for AstraZeneca, Bayer, Bellicum, Bristol-Myers Squibb, Celgene, Dendreon, EMD Serono, Johnson \& Johnson, Oncogenex, Pfizer, Sanofi-Aventis, and Tokai; has received research funding (institution) from Bayer, Endocyte, Innocrin, Johnson \& Johnson, and Sanofi-Aventis; has given expert testimony for Sanofi; and is Co-Chair of the GU Committee for NRG. The authors have no other relevant affiliations or financial involvement with any organization or entity with a financial interest in or financial conflict with the subject matter or materials discussed in the manuscript apart from those disclosed.

The authors thank Heather Nyce of SciStrategy Communications for professional manuscript writing support, funded by Bayer HealthCare Pharmaceuticals. 
Open access

This work is licensed under the Attribution-NonCommercial-NoDerivatives 4.0 Unported License. To view a copy of this license, visit http://creativecommons.org/licenses/by-nc-nd/4.0/

\section{References}

Papers of special note have been highlighted as: $\bullet$ of interest; $\bullet \bullet$ of considerable interest

1. Mundy GR. Metastasis to bone: causes, consequences and therapeutic opportunities. Nat. Rev. Cancer 2(8), 584-593 (2002).

2. Weilbaecher KN, Guise TA, McCauley LK. Cancer to bone: a fatal attraction. Nat. Rev. Cancer 11(6), 411-425 (2011).

3. Brown JE, Sim S. Evolving role of bone biomarkers in castration-resistant prostate cancer. Neoplasia 12(9), 685-696 (2010).

4. Nishimori H, Ehata S, Suzuki HI, Katsuno Y, Miyazono K. Prostate cancer cells and bone stromal cells mutually interact with each other through bone morphogenetic protein-mediated signals. J. Biol. Chem. 287(24), 20037-20046 (2012).

5. Zayzafoon M, Abdulkadir SA, McDonald JM. Notch signaling and ERK activation are important for the osteomimetic properties of prostate cancer bone metastatic cell lines. J. Biol. Chem. 279(5), 3662-3670 (2004).

6. El-Amm J, Aragon-Ching JB. Targeting bone metastases in metastatic castration-resistant prostate cancer. Clin. Med. Insights Oncol. 10(Suppl. 1), 11-19 (2016).

7. Bubendorf L, Schopfer A, Wagner U et al. Metastatic patterns of prostate cancer: an autopsy study of 1589 patients. Hum. Pathol. 31(5), 578-583 (2000).

8. Tannock IF, De Wit R, Berry WR et al. Docetaxel plus prednisone or mitoxantrone plus prednisone for advanced prostate cancer. $N$. Engl. J. Med. 351(15), 1502-1512 (2004).

9. Price PA, Toroian D, Chan WS. Tissue-nonspecific alkaline phosphatase is required for the calcification of collagen in serum: a possible mechanism for biomineralization. J. Biol. Chem. 284(7), 4594-4604 (2009).

10. Cook RJ, Coleman R, Brown J et al. Markers of bone metabolism and survival in men with hormone-refractory metastatic prostate cancer. Clin. Cancer Res. 12(11 Pt 1), 3361-3367 (2006).

11. Guise TA, Mohammad KS, Clines G et al. Basic mechanisms responsible for osteolytic and osteoblastic bone metastases. Clin. Cancer Res. 12(20 Pt 2), 6213s-6216s (2006).

- A review of the mechanisms and therapeutic implications of osteolytic and osteoblastic bone metastases.

12. D'Oronzo S, Brown J, Coleman R. The value of biomarkers in bone metastasis. Eur. J. Cancer Care 26(6), e12725 (2017).

-• A review of the current knowledge of bone metastasis development and recent advances in biomarker research.

13. Rucci N, Teti A. Osteomimicry: how tumor cells try to deceive the bone. Front. Biosci. 2, 907-915 (2010).

- A review of bone metastases and osteomimicry.

14. Lin DL, Tarnowski CP, Zhang J et al. Bone metastatic LNCaP-derivative C4-2B prostate cancer cell line mineralizes in vitro. Prostate 47(3), 212-221 (2001).

15. Knerr K, Ackermann K, Neidhart T, Pyerin W. Bone metastasis: osteoblasts affect growth and adhesion regulons in prostate tumor cells and provoke osteomimicry. Int. J. Cancer 111(1), 152-159 (2004).

16. Zhau HE, He H, Wang CY et al. Human prostate cancer harbors the stem cell properties of bone marrow mesenchymal stem cells. Clin. Cancer Res. 17(8), 2159-2169 (2011).

17. Bitting RL, Armstrong AJ. Potential predictive biomarkers for individualizing treatment for men with castration-resistant prostate cancer. Cancer J. 19(1), 25-33 (2013).

18. Brown JE, Cook RJ, Major P et al. Bone turnover markers as predictors of skeletal complications in prostate cancer, lung cancer, and other solid tumors. J. Natl Cancer Inst. 97(1), 59-69 (2005).

19. Coleman RE, Major P, Lipton A et al. Predictive value of bone resorption and formation markers in cancer patients with bone metastases receiving the bisphosphonate zoledronic acid. J. Clin. Oncol. 23(22), 4925-4935 (2005).

20. Armstrong AJ, Febbo PG. Using surrogate biomarkers to predict clinical benefit in men with castration-resistant prostate cancer: an update and review of the literature. Oncologist 14(8), 816-827 (2009).

21. Fizazi K, Massard C, Smith M et al. Bone-related parameters are the main prognostic factors for overall survival in men with bone metastases from castration-resistant prostate cancer. Eur. Urol. 68(1), 42-50 (2015).

-• Analysis of a contemporary metastatic castration-resistant prostate cancer dataset that identified bone-related parameters associated with longer survival.

22. Guinney J, Wang T, Laajala TD et al. Prediction of overall survival for patients with metastatic castration-resistant prostate cancer: development of a prognostic model through a crowdsourced challenge with open clinical trial data. Lancet Oncol. 18(1), 132-142 (2017).

23. Halabi S, Lin CY, Small EJ et al. Prognostic model predicting metastatic castration-resistant prostate cancer survival in men treated with second-line chemotherapy. J. Natl Cancer Inst. 105(22), 1729-1737 (2013). 
24. Halabi S, Lin CY, Kelly WK et al. Updated prognostic model for predicting overall survival in first-line chemotherapy for patients with metastatic castration-resistant prostate cancer. J. Clin. Oncol. 32(7), 671-677 (2014).

25. Crawford ED, Petrylak D, Sartor O. Navigating the evolving therapeutic landscape in advanced prostate cancer. Urol. Oncol. 35S, S1-S13 (2017).

26. Metwalli AR, Rosner IL, Cullen J et al. Elevated alkaline phosphatase velocity strongly predicts overall survival and the risk of bone metastases in castrate-resistant prostate cancer. Urol. Oncol. 32(6), 761-768 (2014).

- Retrospective study of ALP velocity as an independent predictor of overall survival and bone metastases-free survival in patients with CRPC.

27. Hammerich KH, Donahue TF, Rosner IL et al. Alkaline phosphatase velocity predicts overall survival and bone metastasis in patients with castration-resistant prostate cancer. Urol. Oncol. 35(7), 460.e421-460.e428 (2017).

28. Boegemann M, Schrader AJ, Krabbe LM, Herrmann E. Present, emerging and possible future biomarkers in castration resistant prostate cancer (CRPC). Curr. Cancer Drug Targets 15(3), 243-255 (2015).

29. Petrylak DP, Crawford ED. Biomarkers for the management of castration-resistant prostate cancer: we are not there yet. Target Oncol. 12(4), 401-412 (2017).

-• A review of existing and potential biomarkers for managing CRPC.

30. Mulders PF, De Santis M, Powles T, Fizazi K. Targeted treatment of metastatic castration-resistant prostate cancer with sipuleucel-T immunotherapy. Cancer Immunol. Immunother. 64(6), 655-663 (2015).

31. Drake CG. Prostate cancer as a model for tumour immunotherapy. Nat. Rev. Immunol. 10(8), 580-593 (2010).

32. Gulley JL, Madan RA, Pachynski R et al. Role of antigen spread and distinctive characteristics of immunotherapy in cancer treatment. $J$. Natl. Cancer Inst. 109(4), doi:10.1093/jnci/djw261 (2017).

33. Graff JN, Chamberlain ED. Sipuleucel-T in the treatment of prostate cancer: an evidence-based review of its place in therapy. Core Evid. 10, 1-10 (2015).

34. No authors listed. Provenge ${ }^{\circledR}$ (sipuleucel-T) suspension for intravenous infusion [prescribing information]. Dendreon Corporation, WA, USA (2010).

35. Rehman Y, Rosenberg JE. Abiraterone acetate: oral androgen biosynthesis inhibitor for treatment of castration-resistant prostate cancer. Drug Des. Devel. Ther. 6, 13-18 (2012).

36. Zobniw CM, Causebrook A, Fong MK. Clinical use of abiraterone in the treatment of metastatic castration-resistant prostate cancer. Res. Rep. Urol. 6, 97-105 (2014).

37. Mostaghel EA. Abiraterone in the treatment of metastatic castration-resistant prostate cancer. Cancer Manag. Res. 6, 39-51 (2014).

38. Iuliani M, Pantano F, Buttigliero C et al. Biological and clinical effects of abiraterone on anti-resorptive and anabolic activity in bone microenvironment. Oncotarget 6(14), 12520-12528 (2015).

39. Alex AB, Pal SK, Agarwal N. CYP17 inhibitors in prostate cancer: latest evidence and clinical potential. Ther. Adv. Med. Oncol. 8(4), 267-275 (2016).

40. No authors listed. Zytiga ${ }^{\text {TM }}$ (abiraterone acetate) tablets for oral administration [prescribing information]. Centocor Ortho Biotech, Inc., PA, USA (2011).

41. Schalken J, Fitzpatrick JM. Enzalutamide: targeting the androgen signalling pathway in metastatic castration-resistant prostate cancer. BJU Int. 117(2), 215-225 (2016).

42. Patel NK, Finianos A, Whitaker KD, Aragon-Ching JB. Advanced prostate cancer - patient survival and potential impact of enzalutamide and other emerging therapies. Ther. Clin. Risk Manag. 10, 651-664 (2014).

43. Tran C, Ouk S, Clegg NJ et al. Development of a second-generation antiandrogen for treatment of advanced prostate cancer. Science 324(5928), 787-790 (2009).

44. No authors listed. Xtandi ${ }^{\circledR}$ (enzalutamide) capsules for oral use [prescribing information]. Astellas Pharma US Inc., IL, USA (2012).

45. Pienta KJ. Preclinical mechanisms of action of docetaxel and docetaxel combinations in prostate cancer. Semin. Oncol. 28(4 Suppl. 15), 3-7 (2001).

46. Stein CA. Mechanisms of action of taxanes in prostate cancer. Semin. Oncol. 26(5 Suppl. 17), 3-7 (1999).

47. Zhu ML, Horbinski CM, Garzotto M, Qian DZ, Beer TM, Kyprianou N. Tubulin-targeting chemotherapy impairs androgen receptor activity in prostate cancer. Cancer Res. 70(20), 7992-8002 (2010).

48. Fitzpatrick JM, De Wit R. Taxane mechanisms of action: potential implications for treatment sequencing in metastatic castration-resistant prostate cancer. Eur. Urol. 65(6), 1198-1204 (2014).

49. Kuroda K, Liu H, Kim S, Guo M, Navarro V, Bander NH. Docetaxel down-regulates the expression of androgen receptor and prostate-specific antigen but not prostate-specific membrane antigen in prostate cancer cell lines: implications for PSA surrogacy. Prostate 69(14), 1579-1585 (2009). 
50. No authors listed. Taxotere (docetaxel) injection concentrate, intravenous infusion [prescribing information]. Sanofi-Aventis US LLC, NJ, USA (2015).

51. Mellado B, Jimenez N, Marin-Aguilera M, Reig O. Diving into cabazitaxel's mode of action: more than a taxane for the treatment of castration-resistant prostate cancer patients. Clin. Genitourin. Cancer 14(4), 265-270 (2016).

52. Zhao S, Yu EY. Castrate-resistant prostate cancer: postdocetaxel management. Curr. Opin. Urol. 23(3), 201-207 (2013).

53. Galsky MD, Dritselis A, Kirkpatrick P, Oh WK. Cabazitaxel. Nat. Rev. Drug Discov. 9(9), 677-678 (2010).

54. No authors listed. Jevtana (cabazitaxel) injection, $60 \mathrm{mg} / 1.5 \mathrm{ml}$, for intravenous infusion only [prescribing information]. Sanofi-Aventis U.S. LLC, NJ, USA (2010).

55. Henriksen G, Breistol K, Bruland OS, Fodstad O, Larsen RH. Significant antitumor effect from bone-seeking, alpha-particle-emitting ${ }^{223} \mathrm{Ra}$ demonstrated in an experimental skeletal metastases model. Cancer Res. 62(11), 3120-3125 (2002).

56. Henriksen G, Fisher DR, Roeske JC, Bruland OS, Larsen RH. Targeting of osseous sites with alpha-emitting ${ }^{223}$ Ra: comparison with the beta-emitter ${ }^{89} \mathrm{Sr}$ in mice. J. Nucl. Med. 44(2), 252-259 (2003).

57. Bruland OS, Nilsson S, Fisher DR, Larsen RH. High-linear energy transfer irradiation targeted to skeletal metastases by the alpha-emitter ${ }^{223}$ Ra: adjuvant or alternative to conventional modalities? Clin. Cancer Res. 12 (20 Pt 2), 6250s-6257s (2006).

58. Abou DS, Ulmert D, Doucet M, Hobbs RF, Riddle RC, Thorek DL. Whole-body and microenvironmental localization of radium-223 in naive and mouse models of prostate cancer metastasis. J. Natl Cancer Inst. 108(5), djv380 (2016).

59. Suominen MI, Fagerlund KM, Rissanen JP et al. Radium-223 inhibits osseous prostate cancer growth by dual targeting of cancer cells and bone microenvironment in mouse models. Clin. Cancer Res. 23(15), $4335-4336$ (2017).

60. Suominen MI, Rissanen JP, Kakonen R et al. Survival benefit with radium-223 dichloride in a mouse model of breast cancer bone metastasis. J. Natl Cancer Inst. 105(12), 908-916 (2013).

61. Malamas AS, Gameiro SR, Knudson KM, Hodge JW. Sublethal exposure to alpha radiation $\left({ }^{223}\right.$ Ra dichloride) enhances various carcinomas' sensitivity to lysis by antigen-specific cytotoxic $\mathrm{T}$ lymphocytes through calreticulin-mediated immunogenic modulation. Oncotarget 7(52), 86937-86947 (2016).

62. No authors listed. Xofigo (radium Ra 223 dichloride) Injection, for intravenous use [prescribing information]. Bayer HealthCare Pharmaceuticals Inc., NJ, USA (2013).

63. Bilen MA, Hess KR, Subudhi SK et al. Clinical predictors of survival in patients with castration-resistant prostate cancer receiving sipuleucel-T cellular immunotherapy. Cancer Chemother. Pharmacol. 80(3), 583-589 (2017).

64. Parker C, Nilsson S, Heinrich D et al. Alpha emitter radium-223 and survival in metastatic prostate cancer. N. Engl. J. Med. 369(3), 213-223 (2013).

65. Sartor O, Coleman RE, Nilsson $\mathrm{S}$ et al. An exploratory analysis of alkaline phosphatase, lactate dehydrogenase, and prostate-specific antigen dynamics in the Phase 3 ALSYMPCA trial with radium-223. Ann. Oncol. 28(5), 1090-1097 (2017).

66. Saad F, Carles J, Gillessen S et al. Radium-223 and concomitant therapies in patients with metastatic castration-resistant prostate cancer: an international, early access, open-label, single-arm Phase 3b trial. Lancet Oncol. 17(9), 1306-1316 (2016).

67. George DJ, Nabhan C, Devries T, Whitmore JB, Gomella LG. Survival outcomes of sipuleucel-T Phase III studies: impact of control-arm cross-over to salvage immunotherapy. Cancer Immunol. Res. 3(9), 1063-1069 (2015).

68. Fizazi K, Scher HI, Molina A et al. Abiraterone acetate for treatment of metastatic castration-resistant prostate cancer: final overall survival analysis of the COU-AA-301 randomised, double-blind, placebo-controlled Phase 3 study. Lancet Oncol. 13(10), 983-992 (2012).

69. Chi KN, Kheoh T, Ryan CJ et al. A prognostic index model for predicting overall survival in patients with metastatic castration-resistant prostate cancer treated with abiraterone acetate after docetaxel. Ann. Oncol. 27(3), 454-460 (2016).

70. Ryan CJ, Smith MR, Fizazi K et al. Abiraterone acetate plus prednisone versus placebo plus prednisone in chemotherapy-naive men with metastatic castration-resistant prostate cancer (COU-AA-302): final overall survival analysis of a randomised, double-blind, placebo-controlled Phase 3 study. Lancet Oncol. 16(2), 152-160 (2015).

71. Mikah P, Krabbe LM, Eminaga O et al. Dynamic changes of alkaline phosphatase are strongly associated with PSA-decline and predict best clinical benefit earlier than PSA-changes under therapy with abiraterone acetate in bone metastatic castration resistant prostate cancer. BMC Cancer 16, 214 (2016).

72. Armstrong AJ, Garrett-Mayer ES, Yang YC, De Wit R, Tannock IF, Eisenberger M. A contemporary prognostic nomogram for men with hormone-refractory metastatic prostate cancer: a TAX327 study analysis. Clin. Cancer Res. 13(21), 6396-6403 (2007).

73. Armstrong AJ, Garrett-Mayer E, De Wit R, Tannock I, Eisenberger M. Prediction of survival following first-line chemotherapy in men with castration-resistant metastatic prostate cancer. Clin. Cancer Res. 16(1), 203-211 (2010).

74. Sonpavde G, Pond GR, Berry WR et al. Serum alkaline phosphatase changes predict survival independent of PSA changes in men with castration-resistant prostate cancer and bone metastasis receiving chemotherapy. Urol. Oncol. 30(5), 607-613 (2012).

75. Bahl A, Oudard S, Tombal B et al. Impact of cabazitaxel on 2-year survival and palliation of tumour-related pain in men with metastatic castration-resistant prostate cancer treated in the TROPIC trial. Ann. Oncol. 24(9), 2402-2408 (2013). 
76. Van Soest RJ, Nieuweboer AJ, De Morree ES et al. The influence of prior novel androgen receptor targeted therapy on the efficacy of cabazitaxel in men with metastatic castration-resistant prostate cancer. Eur. J. Cancer 51(17), 2562-2569 (2015).

77. Kantoff PW, Higano CS, Shore ND et al. Sipuleucel-T immunotherapy for castration-resistant prostate cancer. N. Engl. J. Med. 363(5), 411-422 (2010).

78. Small EJ, Schellhammer PF, Higano CS et al. Placebo-controlled Phase III trial of immunologic therapy with sipuleucel-T (APC8015) in patients with metastatic, asymptomatic hormone refractory prostate cancer. J. Clin. Oncol. 24(19), 3089-3094 (2006).

79. Rathkopf DE, Smith MR, De Bono JS et al. Updated interim efficacy analysis and long-term safety of abiraterone acetate in metastatic castration-resistant prostate cancer patients without prior chemotherapy (COU-AA-302). Eur. Urol. 66(5), 815-825 (2014).

80. De Bono JS, Logothetis CJ, Molina A et al. Abiraterone and increased survival in metastatic prostate cancer. N. Engl. J. Med. 364(21), 1995-2005 (2011).

81. Logothetis CJ, Basch E, Molina A et al. Effect of abiraterone acetate and prednisone compared with placebo and prednisone on pain control and skeletal-related events in patients with metastatic castration-resistant prostate cancer: exploratory analysis of data from the COU-AA-301 randomised trial. Lancet Oncol. 13(12), 1210-1217 (2012).

82. Ryan CJ, Smith MR, De Bono JS et al. Abiraterone in metastatic prostate cancer without previous chemotherapy. N. Engl. J. Med. 368(2), 138-148 (2013).

83. Verzoni E, De Giorgi U, Derosa L et al. Predictors of long-term response to abiraterone in patients with metastastic castration-resistant prostate cancer: a retrospective cohort study. Oncotarget 7(26), 40085-40094 (2016).

84. Beer TM, Armstrong AJ, Rathkopf DE et al. Enzalutamide in metastatic prostate cancer before chemotherapy. N. Engl. J. Med. 371(5), 424-433 (2014).

85. Scher HI, Fizazi K, Saad F et al. Increased survival with enzalutamide in prostate cancer after chemotherapy. N. Engl. J. Med. 367(13), 1187-1197 (2012).

86. Salvi S, Casadio V, Conteduca V et al. Circulating AR copy number and outcome to enzalutamide in docetaxel-treated metastatic castration-resistant prostate cancer. Oncotarget 7(25), 37839-37845 (2016).

87. Yamashita S, Kohjimoto Y, Iguchi $\mathrm{T}$ et al. Prognostic factors and risk stratification in patients with castration-resistant prostate cancer receiving docetaxel-based chemotherapy. BMC Urol. 16, 13 (2016).

88. Quinn DI, Tangen CM, Hussain M et al. Docetaxel and atrasentan versus docetaxel and placebo for men with advanced castration-resistant prostate cancer (SWOG S0421): a randomised Phase 3 trial. Lancet Oncol. 14(9), 893-900 (2013).

89. Lara PN Jr., Ely B, Quinn DI et al. Serum biomarkers of bone metabolism in castration-resistant prostate cancer patients with skeletal metastases: results from SWOG 0421. J. Natl Cancer Inst. 106(4), dju013 (2014).

90. Petrylak DP, Tangen CM, Hussain MH et al. Docetaxel and estramustine compared with mitoxantrone and prednisone for advanced refractory prostate cancer. N. Engl. J. Med. 351(15), 1513-1520 (2004).

91. Han KS, Hong SJ. Serum alkaline phosphatase differentiates prostate-specific antigen flare from early disease progression after docetaxel chemotherapy in castration-resistant prostate cancer with bone metastasis. J. Cancer Res. Clin. Oncol. 140(10), 1769-1776 (2014).

92. Matsuyama H, Shimabukuro T, Hara I et al. Combination of hemoglobin, alkaline phosphatase, and age predicts optimal docetaxel regimen for patients with castration-resistant prostate cancer. Int. J. Clin. Oncol. 19(5), 946-954 (2014).

93. De Bono JS, Oudard S, Ozguroglu M et al. Prednisone plus cabazitaxel or mitoxantrone for metastatic castration-resistant prostate cancer progressing after docetaxel treatment: a randomised open-label trial. Lancet 376(9747), 1147-1154 (2010).

94. Nilsson S, Franzen L, Parker C et al. Bone-targeted radium-223 in symptomatic, hormone-refractory prostate cancer: a randomised, multicentre, placebo-controlled Phase II study. Lancet Oncol. 8(7), 587-594 (2007).

95. Nilsson S, Larsen RH, Fossa SD et al. First clinical experience with alpha-emitting radium-223 in the treatment of skeletal metastases. Clin. Cancer Res. 11(12), 4451-4459 (2005).

96. Nilsson S, Strang P, Aksnes AK et al. A randomized, dose-response, multicenter Phase II study of radium-223 chloride for the palliation of painful bone metastases in patients with castration-resistant prostate cancer. Eur. J. Cancer 48(5), 678-686 (2012).

97. Cook G Jr., Parker C, Chua S, Johnson B, Aksnes AK, Lewington VJ. ${ }^{18}$ F-fluoride PET: changes in uptake as a method to assess response in bone metastases from castrate-resistant prostate cancer patients treated with ${ }^{223}$ Ra-chloride (Alpharadin). EJNMMI Res. 1(1), 4 (2011).

98. Uemura H, Uemura H, Matsubara N et al. Safety and efficacy of radium-223 dichloride in Japanese patients with castration-resistant prostate cancer and bone metastases. Int. J. Clin. Oncol. 22(5), 954-963 (2017).

99. Miyazaki KS, Kuang Y, Kwee SA. Changes in skeletal tumor activity on ${ }^{18} \mathrm{~F}$-choline PET/CT in patients receiving ${ }^{223}$ radium radionuclide therapy for metastatic prostate cancer. Nucl. Med. Mol. Imaging 49(2), 160-164 (2015).

100. Scalzi P, Baiocco C, Genovese S, Trevisan A, Sirotova Z, Poti C. Evaluation of bone metastases by ${ }^{18}$ F-choline PET/CT in a patient with castration-resistant prostate cancer treated with radium-223. Urologia 84(1), 61-64 (2017).

101. Sartor O, Coleman R, Nilsson S et al. Effect of radium-223 dichloride on symptomatic skeletal events in patients with castration-resistant prostate cancer and bone metastases: results from a Phase 3, double-blind, randomised trial. Lancet Oncol. 15(7), 738-746 (2014). 
Review Heinrich, Bruland, Guise, Suzuki \& Sartor

102. Heinrich D, Gillessen S, Heidenreich A et al. Changes in alkaline phosphatase (ALP) dynamics and overall survival (OS) in metastatic castration-resistant prostate cancer (mCRPC) patients treated with radium-223 in an international early access program (EAP). Poster presented at the ESMO Congress, 7-11 October 2016, Copenhagen, Denmark.

www.poster-submission.com/esmo2016/visitors/carousel 